La imagen latente. Dirección de fotografía y pedagogía situada

Franco Palazzo, Franco Cerana

Metal (N. $\left.{ }^{\circ} 4\right)$, e001, julio 2018. ISSN 2451-6643

https://doi.org/10.24215/24516643e001

http://papelcosido.fba.unlp.edu.ar/ojs/index.php/metal/

Facultad de Bellas Artes. Universidad Nacional de La Plata

\title{
LA IMAGEN LATENTE DIRECCIÓN DE FOTOGRAFÍA Y PEDAGOGÍA SITUADA
}

\author{
THE LATENT IMAGE \\ A Pedagogical Approach to the Direction of Photography
}

\author{
Franco Palazzo \\ francopalazzo.lp@gmail.com \\ Franco Cerana \\ ceranafranco@gmail.com
}

Facultad de Bellas Artes. Universidad Nacional de La Plata. Argentina

\begin{abstract}
The direction of photography of an audiovisual product is the result of the modes of production from a place, its aesthetics, narrative styles, and representations. The pedagogy of the discipline must be concerned with the context where productions are made. Who are the students? What are their aesthetic interests? From what position do they construct the cinematographic image? A good method to answer these questions consists in analyzing the local productions of graduate students from the institution. This article analyzes the possibility, but also the necessity, the use of local independent production as pedagogical examples in Audiovisual Arts classrooms.
\end{abstract}

\section{Keywords}

Direction of photography; pedagogy; artistic education; educative contexts; production contexts

\section{Resumen}

La dirección de fotografía de un audiovisual es producto de los modos de producción del lugar, sus estéticas, sus formas de narrar, sus representaciones. Una pedagogía de la disciplina debe ser consciente del contexto. ¿Quiénes son sus estudiantes? ¿Cuáles son sus intereses estéticos? ¿Desde qué lugar construyen la imagen cinematográfica? Estudiar los trabajos de quienes se graduaron en la propia institución es un buen método para comenzar a responder estos interrogantes. En el presente artículo se reflexiona sobre el uso de la producción local en las aulas de Dirección de Fotografía.

\section{Palabras clave}

Dirección de fotografía; pedagogía; educación artística; contextos educativos; contextos de producción 
Las materias Iluminación y Cámara abordan el estudio de los conocimientos vinculados al ejercicio de la dirección de fotografía en el marco de las artes audiovisuales. Esta disciplina, aunque está relacionada, en gran medida, con el arte de la fotografía fija, conforma una especificidad autónoma que se remonta a los inicios del cine y que no se ha visto modificada hasta la fecha en sus aspectos troncales. Las directoras y los directores de fotografía, que encarnan ese rol en una producción cinematográfica, son los principales responsables de la dimensión visual de una obra audiovisual. Desde que forma parte de un proyecto en la preproducción, pasando por la instancia de grabación, hasta su exhibición -en cualquiera de la infinita variedad de dispositivos en los que una obra audiovisual puede materializarse ante un espectador - la persona encargada de la dirección de fotografía es quien, mediante la aplicación de sus conocimientos específicos, de pruebas técnicas y de su creatividad y su experiencia, debe garantizar que la imagen sea la mejor para el proyecto. Y cuando hablamos de la mejor imagen, nos referimos tanto a los aspectos visuales como a la capacidad de desarrollar una propuesta que se adecúe al proyecto, teniendo en cuenta aspectos narrativos, genéricos, estilísticos y el contexto de producción.

Según Néstor Almendros (1982), quien ejerza la dirección de fotografía puede servir «para casi todo y para casi nada»:

Sus funciones varían tanto de una película a otra, que no se pueden definir de una manera exacta. Mi trabajo puede limitarse a apretar el botón de la cámara. Y a veces ni eso siquiera, pues alguien, un operador, se encarga de llevar la cámara mientras yo estoy cerca, sentado en una silla plegable con mi nombre escrito detrás. Uno está allí para supervisar la imagen, dar algunos consejos y firmar el trabajo. [...] En el extremo opuesto, un director de fotografía que colabora en una película de pequeño presupuesto con un 
realizador inexperto o principiante, puede decidir no ya la elección de objetivos, sino la naturaleza misma del encuadre, los movimientos de cámara, la coreografía de los actores y, por supuesto, la iluminación, la atmósfera visual de cada escena. Llego incluso a inmiscuirme en la selección de los colores, los materiales y las formas de los decorados y el vestuario (p. 6).

El colectivo de estudiantes de la carrera de Artes Audiovisuales, hoy más que nunca, conoce -aunque sea de manera puramente intuitiva- los alcances y las posibilidades visuales del lenguaje audiovisual. Gracias a las nuevas tecnologías, quien ingresa a la Facultad de Bellas Artes (FBA) de la Universidad Nacional de La Plata (UNLP) ya tiene - desde su niñez, seguramente- una experiencia muy fluida y cotidiana con la producción de imágenes a través de dispositivos electrónicos. Producir imágenes para Youtube, Facebook, Instagram, etcétera, implica la aplicación - consciente o inconsciente- de una serie compleja de operaciones y de conocimientos vinculados a lo tecnológico, así como la puesta en práctica de los códigos visuales y de los modos de comunicación específicos de cada plataforma.

Desde una perspectiva pedagógica, el eje central a la hora de conceptualizar los conocimientos vinculados a esta disciplina no pasa solamente por enseñar una serie de códigos o de reglas visuales que después puedan ser aplicados -o transgredidos-, sino que también es fundamental que quienes cursen estas materias puedan entender qué recursos son necesarios para lograr un determinado resultado estético 0 , dicho a la inversa, qué variedad de imágenes es posible crear con una serie determinada de recursos. Estos últimos están vinculados con el modelo de producción elegido, en primer lugar, a partir de la escala presupuestaria del proyecto, pero también de los contextos sociales y culturales. Tener en cuenta estos elementos es troncal para poder producir la imagen audiovisual con una mirada más abarcativa y orgánica, y permite expandir las posibilidades creativas, estéticas y narrativas. Laura citarella, docente y productora de cine independiente -además de guionista y realizadora-, comenta: «Mi obsesión, y lo que más me interesa, es la relación entre sistemas de producción con la estética. Ese parentesco, en este momento, me parece la base para hacer una película» (Citarella en Ponzinibbio \& Franco, 2015, p. 25).

En esta línea, de forma más específica, nos permitimos afirmar que la dirección de fotografía de un audiovisual también es el resultado de los modos de producción en los cuales está inscrita la obra, con sus estéticas, sus modos de narrar y sus representaciones particulares. 


\section{La producción local, un marco situado}

Para pensar la enseñanza de la dirección de fotografía como una práctica situada y concreta, debemos definir - 0 al menos describir - las características particulares de la producción audiovisual local, que involucra a una importante población graduada y estudiante de la UNLP. La producción audiovisual platense se caracteriza por su carácter predominantemente independiente y por la relación fraternal entre realizadores y casas productoras, que se reconocen entre sí con similares virtudes y déficits, y deciden auxiliarse a través de diversos modos de coproducción solidaria. El ser independiente conlleva que no solo deban autosustentarse, sino que ellos mismos administren sus recursos y no estén sujetos a las decisiones de grandes productoras o de grupos mediáticos.

El cortometraje Carto de Ramona (1966), de Alejandro Malowicki, puede ser tomado como ejemplo y como antecedente de este modo de producir. Es un cortometraje de ficción realizado en el marco de la cátedra Realización IV, en ese entonces a cargo de Humberto Ríos, que cuenta la historia de una joven del interior que se muda a Buenos Aires en busca de trabajo y se convierte en vendedora ambulante de café. El film es un claro ejemplo de cómo las limitaciones técnicas y económicas pueden transformarse en rasgos estéticos generadores de identidad. Los realizadores, influenciados por el Free-Cinema inglés, decidieron filmar todo el cortometraje con una modalidad documental, insertando a la actriz en situaciones y en contextos reales, algunas veces, incluso, con la cámara oculta. De esa manera, logran, trabajando con escaso material virgen y utilizando solo luz natural, una especial sensación de realidad. "Lo esencial era hacer verosímil lo reconstruido, que de todas maneras estaba tomado de la realidad. En algunos segmentos del corto creo que eso está logrado y en otros no, pero esa idea de la reconstrucción de la realidad era lo que más nos motivaba» (Malowicki en Vallina y otros, 2006, p. 52).

\section{Figura 1. Carta de Ramona (1966),} Alejandro Malowicki
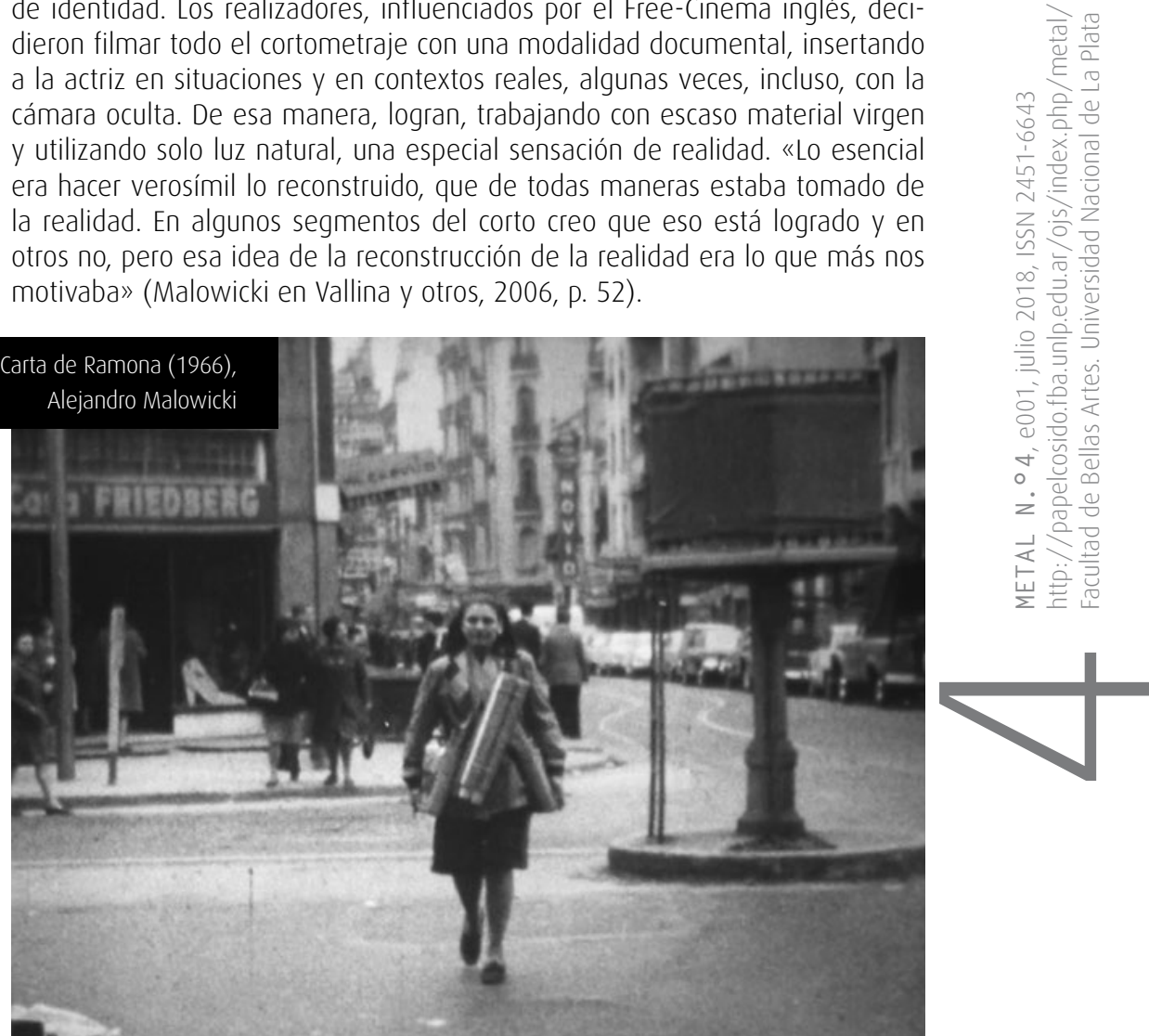
Al seguir esta línea, podemos ver su continuidad en un film contemporáneo como Los Muertos 2 (2016), que nació como un trabajo curricular también en el marco de la cátedra Realización IV y se convirtió en la ópera prima de Manque La Banca. Tanto el guion como el diseño de la estética visual fueron desarrollados a partir de los elementos con los que contaba la producción y las locaciones que se conocían de antemano, teniendo en cuenta el uso de ciertos lentes y de una cámara en particular. Eso, según cuenta Pablo Huerta (2018), el director de fotografía, no generó limitaciones, sino que, por el contrario, se concibió como un punto de partida para la experimentación visual. Se utilizaron lentillas de efecto y caireles delante del lente para lograr distintos tipos de textura en la imagen, que definieron la singular estética del largometraje. Asimismo, se trabajó casi enteramente con luz natural en determinadas horas del día para obtener una imagen más rica en contraste y, a su vez, para lograr una mayor rapidez en el plan de rodaje.

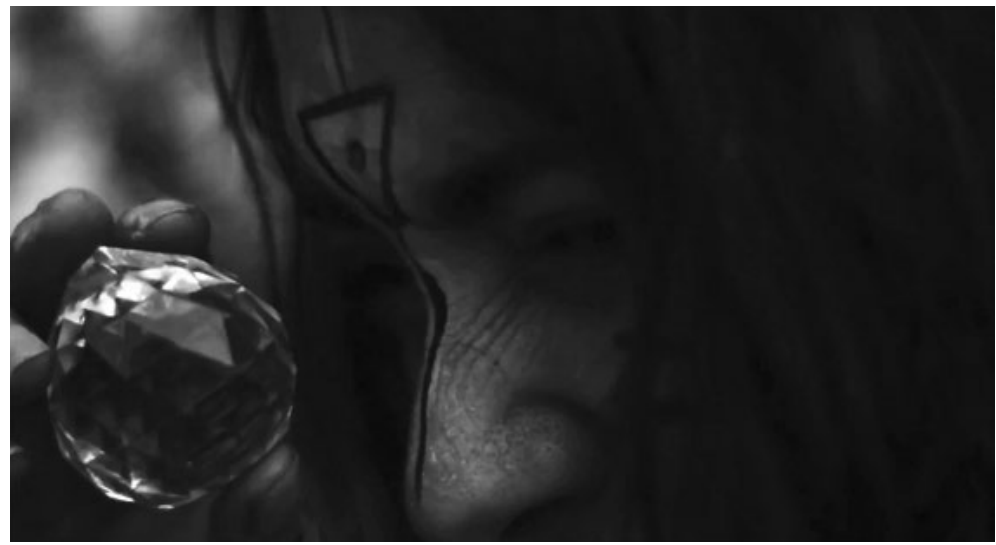

Figuras 2 y 3. Los muertos 2 (2016), Manque La Banca

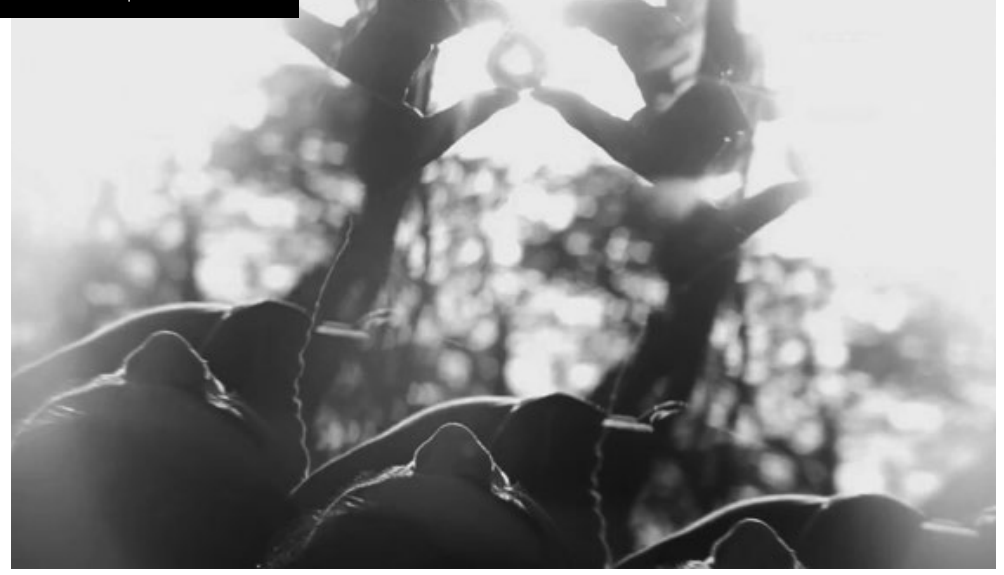


Otro ejemplo similar es el de Tejen (2014), tesis de grado y ópera prima de Pablo Rabe. En ese largometraje de género fantástico se elaboró una propuesta fotográfica general cuya principal característica fue el diseño de un esquema de luz muy simple a partir de una investigación exhaustiva de referentes visuales. Así, se utilizaron sistemas de iluminación que permitían al camarógrafo moverse libremente y registrar desde varios ángulos durante una misma toma. De esa forma, la propuesta estética del film no solo se diseñó en favor de ciertos resultados plásticos, sino que también posibilitó trabajar con pocos elementos técnicos y reducir, considerablemente, el tiempo de rodaje.

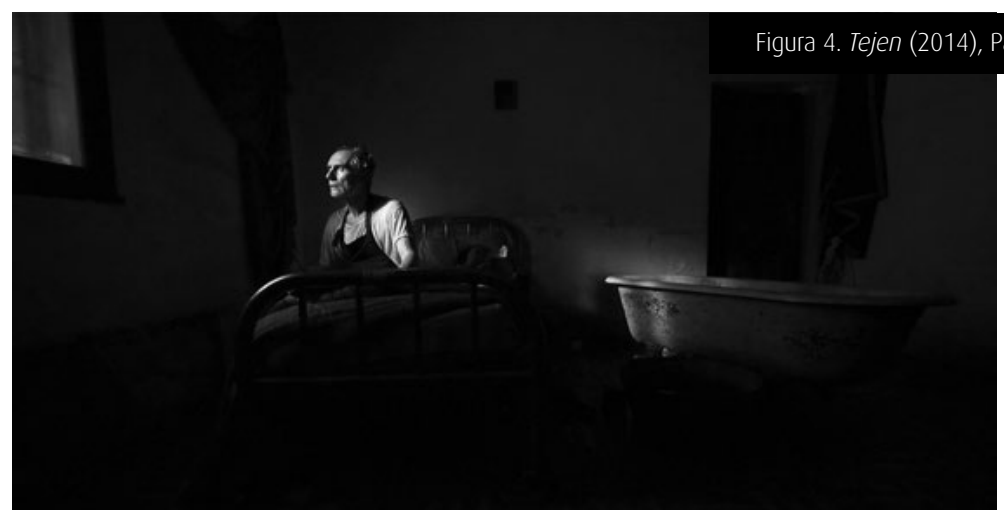

El audiovisual platense se ha empeñado en demostrar que con medios limitados se pueden lograr grandes resultados, siempre y cuando se tengan en cuenta estas condiciones desde la génesis creativa del proyecto. Si bien estos modos de concebir la producción audiovisual son frecuentemente utilizados de manera universal, en la región $-y$, particularmente, en las producciones de estudiantes y de graduados de la UNLP - conforman un rasgo identitario que consolida al cine platense como un movimiento particular.

Desde el punto de vista de la dirección de fotografía, lo particular es que la persona encargada de ese rol suele formar parte del proyecto desde el germen del mismo, definiendo las estrategias para administrar los recursos de la mejor manera posible, convirtiéndose, al fin y al cabo, en un productor más. Como mencionamos, el diseño de la imagen está supeditado al diseño de producción.

Tal como señala Agustín Lostra (2016): «el gesto de gran parte del audiovisual local por su corta proyección en materia de exhibición, por sus condiciones de producción autogestivas y entre amigxs, por su falta de autoconciencia, por sus temáticas 
comunes, es muchas veces un gesto adolescente» (p. 56). La imagen platense es, entonces, una imagen a veces impulsiva, a veces experimental, pocas veces segura de sí misma, en ocasiones sumamente premeditada, en otras azarosa y arriesgada, pero siempre resultado de interminables charlas entre amigos y compañeros. Una creciente conciencia sobre la propia producción -que permite el desarrollo de estilos y de estéticas que se adaptan a la infraestructura de cada proyecto particular-, sumada al aumento considerable de estudiantes de Artes Audiovisuales en los últimos años y al acceso a dispositivos técnicos como consecuencia de los avances tecnológicos, ha posibilitado un incremento cualitativo y cuantitativo de la actividad audiovisual local. Como ejemplo tangible de este fenómeno se puede ver que mientras en 2004 en el Festival Internacional de cine de Mar del Plata participaban seis producciones hechas en la ciudad (El Día, 2004), para 2016 la cifra ascendía a diez, además de la presentación de Lo imagen primigenio: un enfoque multidisciplinar del cine, un libro de análisis cinematográfico editado por los integrantes de Lo Cueva de Chouvet, una revista de crítica cinematográfica local (El Día, 2016). A esto podemos agregar la fundación en 2016 del Movimiento Audiovisual Platense (MAP), conformado por un grupo de realizadores, de productores y de docentes que se nuclea, entre otras cosas, para poner en valor el patrimonio audiovisual regional e intentar recuperarlo a través de un archivo fílmico.

En este marco existe de manera cada vez más tangible una necesidad de definir al cine local, de indagar sobre sus características, su identidad. La revista Pulsión, otra publicación independiente de análisis y de crítica cinematográfica que integra constantemente entre sus temas de indagación problemáticas de la producción local, es un claro ejemplo de este proceso. En una nota editorial titulada "¿Qué es el Cine Platense?», se afirma, a modo de manifiesto: «Nuestra forma de acompañar este proceso es la reflexión, que permite enriquecer la obra, ya que esta es el mejor instrumento para introducirnos en el imaginario colectivo» (Pulsión. Revisto de cine, 2016, p. 7).

\section{La dirección de fotografía en las aulas}

De este modo, al concebir la reflexión sobre la identidad como un valor fundamental de la producción local, la formación académica de los estudiantes de Artes Audiovisuales de la UNLP es clave, ya que permite vehiculizar y acompañar en gran medida estos procesos. Hay que tener en cuenta que la FBA reúne, entre estudiantes y graduados, a la amplia mayoría de las realizadoras y los realizadores audiovisuales de la región. Por esta razón, incorporar dentro de la enseñanza de la dirección de fotografía ejemplos de sus producciones es una manera de transmitir un conocimiento esencial. 
Durante nuestros primeros años como estudiantes en la FBA - entre 2005 y 2006- poco supimos sobre qué producían quienes egresaban de nuestra institución. Solo se hacía alguna referencia a Carlos Sorín y cada tanto se mencionaba a un tal Raymundo Gleyzer, dos estudiantes de la antigua carrera. Algunos se atrevieron a hablarnos sobre un grupo de alumnos que estaban haciendo películas de terror: la productora PauraFlics, que producía incansablemente cine de género -y posteriormente alcanzaría prestigio internacional- Se trataba de comentarios al pasar. En ninguna de las cuatro materias relacionadas con la dirección de fotografía analizamos una producción realizada en nuestra ciudad por quienes en unos años serían nuestros colegas. Cómo se trabaja en nuestra ciudad, qué equipos se usan, qué piensan los directores de fotografía locales sobre la imagen, sobre el cine, sobre el arte y sobre la política fueron preguntas que rondaron en nuestra cabeza hasta que crecimos y conocimos a los productores locales, al tiempo que nos convertíamos en parte de ese circuito.

Diez años después, durante una clase de Dirección de Fotografía en la localidad bonaerense de Pigüé, cuando se explicaron las cualidades plásticas de un Fresnel HMI -una luminaria de alto costo, de uso habitual en el cine comercial e industrial-, un estudiante planteó que le servía muy poco aprender aquello porque jamás tendría acceso a este tipo de dispositivo en su ciudad. En parte tenía razón: no se estaba teniendo en cuenta su contexto de producción, los modos en que suelen producir imágenes en Pigüé, su pensamiento sobre la imagen. Ni siquiera se había considerado qué tipo de audiovisuales producían quienes estudiaban y quienes egresarían de esa carrera. Se estaba dictando la misma clase que podría haberse dado en Madrid, La Paz o en cualquier otro lugar del mundo de habla hispana.

Si tomamos en cuenta las situaciones mencionadas a modo de ejemplo, se vuelve evidente que, como docentes universitarios - además de realizadores-, nos resulta indispensable abordar estas problemáticas desde la pedagogía: pensar cuáles son las herramientas que nos permiten vincular esta serie de ideas con el trabajo dentro del aula o, dicho de otro modo, transformar la reflexión en situación educacional. Es pertinente entonces incorporar al análisis la categorización que realiza Elliot Eisner (1979) sobre los elementos que conforman el currículum de una asignatura. Si entendemos el currículum explícito como los contenidos dictados en una materia, presentes en el plan de estudios, el currículum implícito estaría representado por normas o por valores no expresados abiertamente, resultado de ciertas acciones que se desarrollan en la institución educativa, como los modos de abordar los temas, el tiempo que se le dedica a cada uno, etcétera. Elementos que forman parte de la situación pedagógica, pero que no aparecen en el programa de estudios. Eisner sostiene 
que estos componentes actúan de modo más profundo y permanente en la educación del estudiante que los que se detallan en el currículum explícito. De esta manera, un docente de Dirección de Fotografía debe ser consciente de que, por ejemplo, si de diez audiovisuales que se analizan en clase, nueve son europeos, se construye la idea de que las producciones europeas merecen mayor atención que las de otra región. Lo mismo sucedería en cuanto al género, si nueve de ellos fueran realizados por directores y no directoras.

Por su parte, siguiendo con las categorías de Eisner (1979), el currículum nulo está conformado por aquellos procesos intelectuales que se dejan de lado y por los contenidos que no están presentes en el currículum explícito. En ese sentido, la determinación de incluir o de excluir el estudio de producciones locales es una decisión de carácter ideológico, político y filosófico. Excluir los audiovisuales locales de las aulas de Dirección de Fotografía es excluir también la producción de nuestros propios estudiantes, sus miradas, sus exploraciones estéticas.

\section{Estudiar los límites, ampliar horizontes}

Considerar las particularidades regionales de los procesos que intervienen en el diseño de la imagen audiovisual a la hora de pensar estrategias pedagógicas contribuye a la producción de un aprendizaje significativo, tal como lo define el pedagogo David Ausubel (1983). A diferencia del aprendizoje mecónico, memorístico y coyuntural, el significativo es un aprendizaje más resistente al olvido, porque tiene sus bases en la relación lógica, psicológica y afectiva, entre los contenidos del currículum y los conocimientos del estudiante. Mientras en el primero el acto pedagógico se transforma en una mera transmisión de conceptos carentes de sentido para el educando, en el segundo caso se produce una motivación para aprender gracias a que se incorporan en el proceso el contexto y los saberes previos del estudiante.

Si el universo de modos de representación visual que se brinda al grupo de estudiantes se encuentra fuera de sus posibilidades de producción, no solo no se los estará formando como profesionales de un modo integral, sino que también se los conducirá a situaciones de frustración. Si en las aulas de Dirección de Fotografía se cae en la tentación de mostrar sólo los ejemplos que nos dicta la American Cinematographer - Revista de la Asociación de Directores de Fotografía de Estados Unidos (ASC) - corremos el riesgo de desaprovechar valiosas oportunidades en la formulación de una perspectiva emancipatoria que nos devuelva los medios para una producción de sentido significativa. Como afirma Daniel Belinche (2011), la crisis actual es tributaria de «la ruptura del arte oficial con la vida cotidiana de la mayor parte de la población del país» (p. 90). 
No obstante, es preciso aclarar que no por esto debemos limitar los horizontes de expectativas del estudiante a la producción preexistente en su contexto. Como ya mencionamos, hace poco un joven nos señaló que jamás conseguiría un determinado tipo de imagen porque nunca iba a tener acceso a una luminaria tal como un HMI. Que surja esta idea en un estudiante universitario es inconcebible por varios motivos. En primer lugar, porque si se comprende cuáles son las cualidades plásticas de esta luminaria, posiblemente se pueda generar el tipo de imagen buscada prescindiendo de ese equipamiento específico. Y, en segundo lugar, porque como docentes universitarios debemos incentivar al estudiante para que supere sus capacidades, renueve creativamente el escenario artístico y crezca como profesional.

Por último, como propone Ausubel, debemos construir desde el contexto del estudiante y a partir de sus conocimientos previos. Creemos que la formación en dirección de fotografía debe propiciar un desarrollo creativo a través del cual el grupo de estudiantes pueda plantearse objetivos compatibles con sus intereses $y$, al mismo tiempo, se prepare para entender y para adaptarse a los esquemas de trabajo posibles. De esta manera, podrá explotar la potencialidad visual de cada proyecto a partir de un conocimiento profundo de lo que implica ser un director o una directora de fotografía en el contexto donde se produzca la obra.

\section{Referencias}

Almendros, N. (1982). Díos de una cámara. Barcelona, España: Seix Barral. Ausubel, D., Novak, J. y Hanesian, H. (1983). Psicología educativa: un punto de visto cognoscitivo. Ciudad de México, México: Trillas.

Belinche, D. (2011). Arte, poética y educación. La Plata, Argentina: Facultad de Bellas Artes. Universidad Nacional de La Plata.

Eisner, E. W. (1979). The educational imagination: On the design and evaluation of school programs. Nueva York, Estados Unidos: Macmillan.

ElDía(21denoviembrede2016). LaUsinalocalsemudaaLaFeliz.ElDía. Recuperado dehttps://www.eldia.com/nota/2016-11-21-la-usina-local-se-muda-a-la-feliz El Día (8 de marzo de 2004). Filmes de la Carrera de Cine. El Día. Recuperado de https://www.eldia.com/nota/2004-3-8-filmes-de-la-carrera-de-cine-en-elfestival-de-mar-del-plata

Huerta, P. (2018). Entrevisto a Pablo Huerto, sobre su trabajo como director de fotografía de Los Muertos 2 y T.R.A.P. La Plata. Puede pedirse a <francopalazzo. Ip@gmail.com>.

La Banca, M. (Dir.). (2016). Los Muertos 2 [Largometraje]. Argentina: PARQUEE. Lostra, A. (2016). Como frutas al sol: sobre lentes, chicles, mochilas y cables. Pulsión. Revisto de cine, (4), 51-57. 
Malowicki, A. (Dir) (1966). Corto de Romono [Cortometraje]. Argentina: Universidad Nacional de La Plata.

Pulsión. Revista de cine. (2016). ¿Qué es el cine platense? Pulsión. Revisto de cine,

7.

Ponzinibbio, P. y Franco, I. P. (2015). Estéticas de la producción. Pulsión. Revisto de cine, (2), 25-29.

Rabe, P. (Dir.). (2014). Tejen [Largometraje]. Argentina: Más Ruido.

Vallina, C., Massari, R. y Peña, F. (2006). Escuela de cine Universidad Nocional de Lo Plata: creación, rescate y memorio. La Plata, Argentina: Universidad Nacional de La Plata. 